\title{
0091 SCHOOL-BASED PROGRAM FOR INJURY PREVENTION AND SAFETY PROMOTION IN ISMAILIA CITY, EGYPT
}

H El-Sayed*, S Gad*, H Saied, D Gamal Correspondence: Department of Pediatrics, Suez Canal University Hospital, Faculty of Medicine, Suez Canal University, Ismailia, Egypt

10.1136/ip.2010.029215.91

Objectives To determine the pattern, risk factors and consequences of injuries among school children, and to implement an injury control program in preparatory school in Ismailia city and to evaluate its impact on the knowledge and behaviour of the students.

Design cross-sectional school-based study of selected preparatory school in Ismailia city, followed by a cohort prospective school-based study to implement injury control program and to evaluate its impact.

Methodology Personal and demographic characteristics of the recruited students and data on injuries that needed medical care or caused activity restriction during the last year were collected. Educational and training program targeting school children was developed and implemented in the chosen school, aiming at improving students' knowledge about injury prevention and first aid for injuries. The program included series of lectures, posters, video-presentations and practical injury first aid training program.

Results The study included 197 pupils with a mean age of $13.16+1.61$ years. Incidence of injuries among school children was $35.5 \%$. The most common external causes of injuries sustained by the children were falls (44\%) and near drowning (16\%). The study revealed significant lack of knowledge concerning causes, risk factors, prevention and first aid for injuries among the studies pupils. Children knowledge about these parameters improved significantly after the health promotion and training program implementation.

Conclusions There is great need for safety promotion program for injury prevention and for injury first aid training for school children. This program should also include improvement of safety measures at schools, streets and at home. 